Research Article

\title{
X-Ray Diffraction Technique for Residual Stress Measurement in NiCrMo Alloy Weld Metal
}

\author{
Vladimir Ivanovitch Monine $\mathbb{D}^{1},{ }^{1}$ João da Cruz Payão Filho, ${ }^{1}$ Rodrigo Stohler Gonzaga $\mathbb{D}^{1},{ }^{1}$ \\ Elisa Kimus Dias Passos, ${ }^{1}$ and Joaquim Teixeira de Assis ${ }^{2}$ \\ ${ }^{1}$ Metallurgical and Materials Program, Universidade Federal do Rio de Janeiro, Av. Horácio Macedo 2030, Cidade Universitária, \\ 68505 Rio de Janeiro, Brazil \\ ${ }^{2}$ Mechanical Engineering Department, Instituto Politécnico de Nova Friburgo, Universidade do Estado do Rio de Janeirio, \\ Rua Bonfim 25, Vila Amélia, 28625-570 Nova Friburgo, RJ, Brazil
}

Correspondence should be addressed to Vladimir Ivanovitch Monine; monvlad@mail.ru

Received 2 July 2018; Revised 16 November 2018; Accepted 22 November 2018; Published 16 December 2018

Academic Editor: Paolo Ferro

Copyright (c) 2018 Vladimir Ivanovitch Monine et al. This is an open access article distributed under the Creative Commons Attribution License, which permits unrestricted use, distribution, and reproduction in any medium, provided the original work is properly cited.

\begin{abstract}
In the present work, residual stresses in nickel-based (Ni 625) superalloy weld metal of a $9 \% \mathrm{Ni}$ steel-welded joint were measured by $\mathrm{X}$-ray diffraction (XRD). This technique presents some difficulties in performing measurements in coarse and preferentially oriented weld metal microstructures. It is proposed a preliminary surface treatment by rotating steel wire brushing to perform the stress analysis through XRD technique possible for this kind of material. Stress measurements with proposed XRD technique showed that the stress state in Ni 625 weld metal on the outside surface of the welded joint is characterised by tensile stresses in the transverse and longitudinal directions, while compressive transverse and tensile longitudinal residual stresses are developed in the root pass region.
\end{abstract}

\section{Introduction}

The $9 \% \mathrm{Ni}$ steel, high alloy ferritic cryogenic steel characterised by high mechanical resistance and excellent toughness in low temperatures, has been used until the present moment mostly in the oil and gas industry. Enhaced oil recovery (EOR) and $\mathrm{CO}_{2}$ capture and storage stimulate the implementation of $\mathrm{CO}_{2}$ injection systems in several oil fields around the world. In some reservoirs, where high pressure is needed to perform the EOR, the $9 \% \mathrm{Ni}$ steel was selected as the principal material to manufacture this injection system. This new $9 \% \mathrm{Ni}$ steel application has required the development of thick seamless pipe, by hot rolling Mannesmann process, capable of withstanding high service pressure.

The equipment construction is achieved mainly due to materials joining through welding processes. The $9 \% \mathrm{Ni}$ steel is often welded with nickel-based superalloy 625 because of the similar thermal expansion and high toughness in cryogenic temperatures presented in these materials.

An important issue regarding welding procedure is the residual stresses generated in the welded joint, including the fusion zone (FZ), the heat affected zone (HAZ), and the adjacent base metal (BM). Compressive and tensile residual stresses arise in a welded joint due to localised heating and subsequent fast cooling. Residual tensile stress in a welded joint decreases its fatigue life and corrosion resistance, contribute to its rupture due to buckling, or increase the probability of its failure when combined with other causes [1-5]. In this sense, design, manufacturing, and service conditions of welded joints must be thoroughly evaluated with assertive stress state information, especially in the FZ, where residual tensile stress is found. However, microstructure of FZ characterised by coarse and preferentially oriented grains leads to the X-ray diffraction residual stress measurement a challenge task.

There are several experimental techniques used for stress measurement $[6,7]$. Among the nondestructive methods, the neutron diffraction (ND) and the X-ray diffraction (XRD) techniques are widely used for residual stress measurements $[8,9]$. High penetration of neutrons and developments of spallation neutron sources and TOF diffractometers expand the application of ND techniques in engineering areas, 
in particular, for direct measurements of residual stress distribution in welded components [10]. However, neutron diffraction measurements require special and complex equipment.

$\mathrm{XRD}$ technique is more available, easy to use, precise, and accurate. However, there are some difficulties in stress measuring both for neutron and X-ray diffraction methods in weld metals characterised with preferential orientated and coarse grain microstructure. In the case of nonferrous metals and its alloys, especially nickel alloys, such microstructure features can make difficult the analysis of XRD weld metal stress state $[11,12]$.

In this sense, the principal objective of this work is the development of XRD procedure to measure residual stress in coarse grain weld metal microstructure and apply it on the weld metal residual stress determination of $9 \% \mathrm{Ni}$ steel welded with 625 nickel-based superalloy.

\section{Experimental Details}

In this work, it was analysed a quenched and tempered $9 \% \mathrm{Ni}$ steel pipe butt joint, with $219.1 \mathrm{~mm}$ ( 8 inches) outside diameter and $31.7 \mathrm{~mm}$ (1.25 inches) thickness that was girth welded with GTAW (root and hot weld passes) and SMAW (fill and cap weld passes). The applied filler metal was the Nibased superalloy 625 . The welding process, parameters, and variables used to weld the $9 \% \mathrm{Ni}$ steel pipe butt joint are shown in Table 1. After the welding, the joint was heat treated at $565^{\circ} \mathrm{C}$ for $2 \mathrm{~h}$ with heating and cooling rates equal to $150^{\circ} \mathrm{C} / \mathrm{h}$ and $315^{\circ} \mathrm{C} / \mathrm{h}$, respectively.

For microstructure analysis and XRD stress measurements on the outside and inside surfaces, the weld joint was cut as shown in Figure 1.

The microstructure of the root and cap passes of the Nibased superalloy 625 weld metal were examined with optical microscopy after the stress relief heat treatment. The metallographic specimens were prepared according to standard metallographic techniques and revealed with Lucas' reagent (electrolytic etching, $2 \mathrm{~V}$ during $20 \mathrm{~s}$ ). Figure 2(a) presents the weld metal locations analysed by optical microscopy.

The microstructure of the weld metal cap pass was analysed with electron backscattered diffraction (EBSD) in a FEI Quanta 450 scanning electron microscopy with Bruker $e^{-}$Flash model with $20 \mathrm{kV}$, steps sizes of 11.93 and $0.46 \mu \mathrm{m}$, for overall last bead weld metal and the superficial layer, respectively. Acquired data were analysed using Bruker ESPRIT commercial software. The samples were prepared according to standard metallographic techniques and a final automated polishing with $0.04 \mu \mathrm{m}$ colloidal silica solution for 1 hour.

The weld surface can be cleaned by different means and, in this work, it was done with the aid of stainless steel rotating wire brush. This cleaning method deforms and introduces residual stresses in the surface microstructure that misleads the residual stress measurements, especially the XRD one. Therefore, to obtain correct results of residual stress after welding, the layer after brushing must be removed by chemical or electrochemical means. In this work, a thin surface layer $(10 \mathrm{~mm} \times 10 \mathrm{~mm}$ area and $0.15 \mathrm{~mm}$ to $0.20 \mathrm{~mm}$ depth) was removed by electrolytic polishing. Firstly, XRD residual stress measurements were performed on the weld metal cap pass after electrochemical polishing of the distorted superficial layer and on the face of the root pass weld metal in the as-welded condition, as shown in Figure 2(b) (location 1) and in Figure 2(c). Secondly, residual stress measurements were performed after brushing on three locations of the cap passes weld metal (locations 2, 3 , and 4 in Figure 2(b)) and on the root pass weld metal brushed in the same way as the outside surface of the $9 \% \mathrm{Ni}$ steel weld metal.

The XRD residual stress measurements were performed using mini X-ray diffractometer with position-sensitive detector. This detector decreases the residual stress measurement time, increases the precision, and improves the experimental data processing. A special collimator was designed to facilitate the sample positioning for stress measurement. The incident radiation area is equal to $0.5 \mathrm{~mm} \times$ $2 \mathrm{~mm}$ which is smaller than the curvature radius of a single weld bead. Figure 3 presents the X-ray diffractometer employed in this work.

\subsection{Methodology of X-Ray Diffraction Stress Measurements.} In the present paper, the $\sin ^{2} \psi$ method, based on strain analysis of elasticity theory [3] and diffraction theory $[4,5]$, was used to determine the residual stress. The polar coordinate system is the most appropriate coordinate system to express the principal equations of XRD methodology of stress measurement. Figure 4 shows the strain component in arbitrary direction for three-dimensional stress state in polar coordinates.

Considering that the perpendicular stress $\sigma_{3}$ on the body surface is equal to zero, the strain component in an arbitrary direction can be written as

$$
\varepsilon_{\varphi \psi}=\frac{1+\nu}{E} \sigma_{\varphi} \sin ^{2} \psi-\frac{\nu}{E}\left(\sigma_{1}+\sigma_{2}\right),
$$

where $\varphi$ and $\psi$ are azimuthal and polar angles, respectively; $E$ and $v$ are elastic constants for the material (220) reflections in XRD stress measurements; $\sigma_{1}$ and $\sigma_{2}$ are the principal stresses; and $\sigma_{\varphi}$ is the analysed stress component in the $\varphi$ direction. On the other hand, the strain $\varepsilon_{\varphi \psi}$ can be expressed in terms of X-ray diffraction as

$$
\varepsilon_{\varphi \psi}=\frac{d_{\varphi \psi}-d_{0}}{d_{0}}=-\cot \theta_{0}(\Delta \theta)=-\cot \theta_{0}\left(\theta_{\varphi \psi}-\theta_{0}\right),
$$

where $d_{\varphi \psi}, d_{0}, \theta_{\varphi \psi}$, and $\theta_{0}$ are interplanar distances and diffraction angles for stressed and unstressed materials, respectively. We can equate the right hand sides of equations (1) and (2) to express the diffraction angle $\theta_{\varphi \psi}$ as

$$
\theta_{\varphi \psi}=\theta_{0}-\sigma_{\varphi} \frac{(1-v)}{E} \frac{\sin ^{2} \psi}{\cot \theta_{0}}-\frac{v}{E}\left(\sigma_{1}-\sigma_{2}\right) .
$$

The linearity of $\theta_{\varphi \psi}=f\left(\sin ^{2} \psi\right)$ allows to apply the linear regression for experimental data processing and residual stress calculation. The final equation for determination of analysed stress component is 
TABLE 1: Parameters and variables used to weld the $9 \%$ Ni steel pipe butt joint with the GTA and SMA processes using Ni-based superalloy 625 .

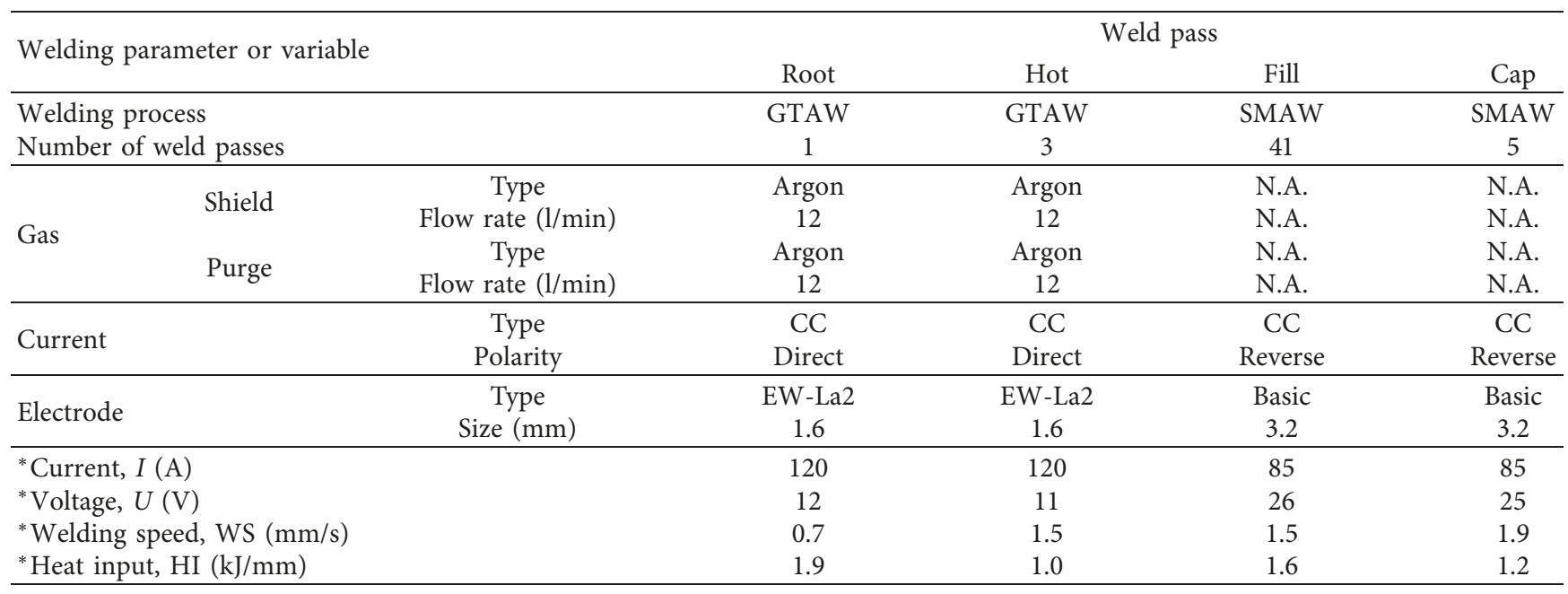

${ }^{*}$ Mean value. N.A. $=$ not applicable.

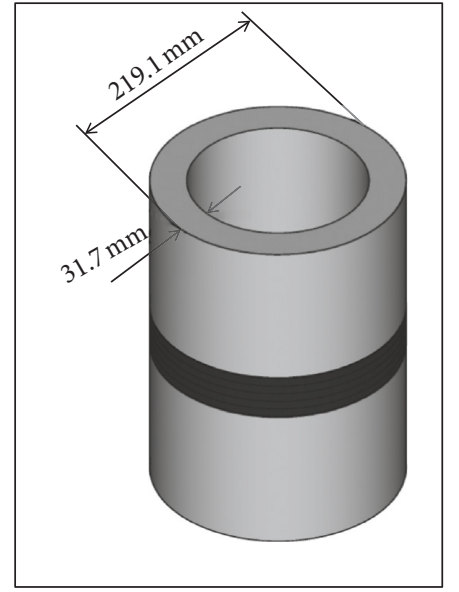

(a)

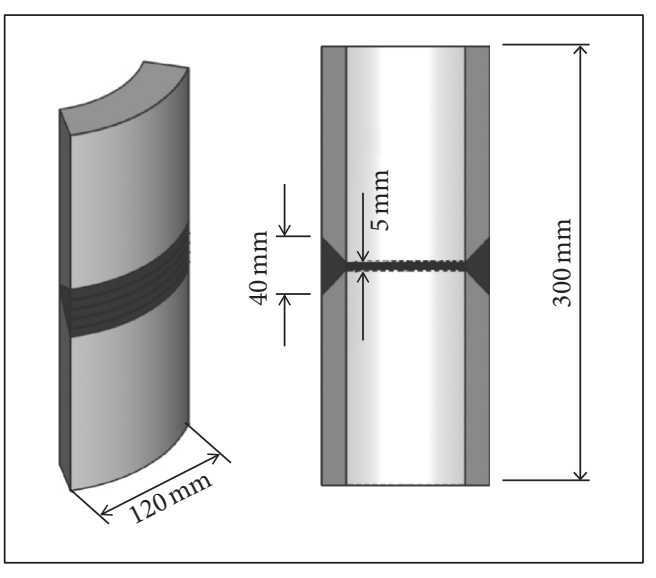

(b)

FIGURE 1: (a) 9\%Ni steel-welded tubular joint. (b) Specimen used in the metallographic analysis and residual stress measurements.

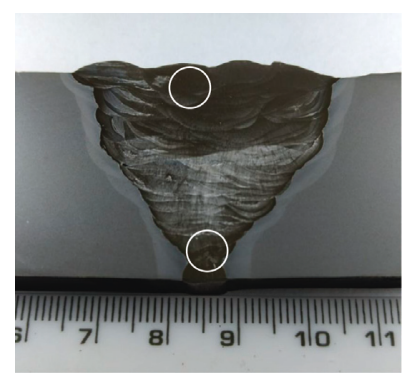

(a)

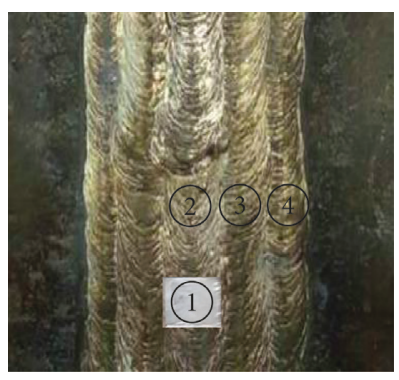

(b)

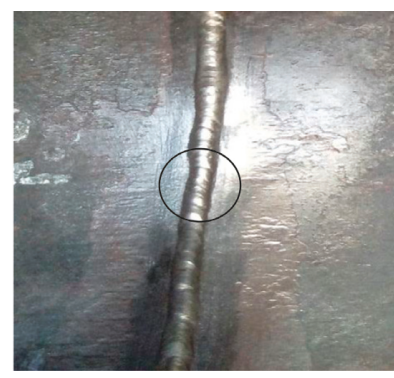

(c)

FIGURE 2: (a) Cross section of the 9\%Ni steel-welded joint: locations (hot and cap weld passes) where metallographic analysis was performed. (b) Locations where XRD residual stress measurements were performed in cap weld passes after brushing (locations 2, 3, and 4). (c) Electrolytic polishing (location 1) and root weld pass location in as-welded and brushed conditions.

$$
\sigma_{\varphi}=-\frac{E}{1+\nu} \cot \theta_{0}\left(\theta_{\psi=90}-\theta_{\psi=0}\right)
$$

where $\left(\theta_{\psi=90}-\theta_{\psi=0}\right)$ is the tangent of the straight line $\theta_{\varphi \psi}=$ $f\left(\sin ^{2} \psi\right)$ obtained by the linear regression.
Therefore, the $\sin ^{2} \psi$ method consists in measurements of diffraction line position at different $\psi$ angles. Figure 5 illustrates the X-ray measurements of longitudinal stress component corresponding to direction parallel to the weld direction. Figure 5(c) shows the collimator alignment with 


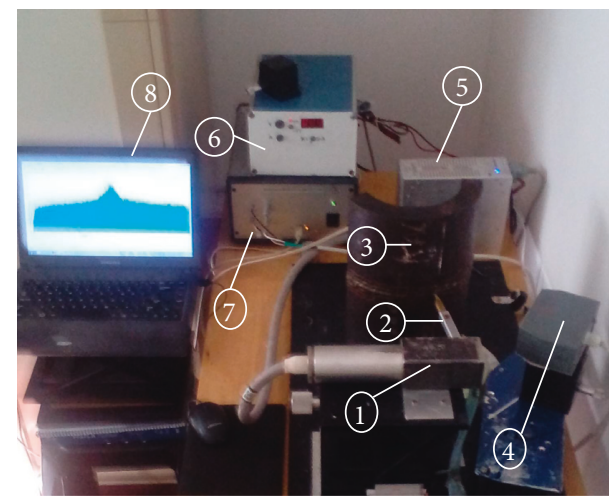

Figure 3: General view of X-ray diffractometer: (1) low-power Xray tube, (2) collimator with tips, (3) piece of analysed pipe, (4) position-sensitive X-ray detector, (5) high-voltage source and Xray tube filament, (6) X-ray source operating control block, (7) detector operation control block, and (8) PC.

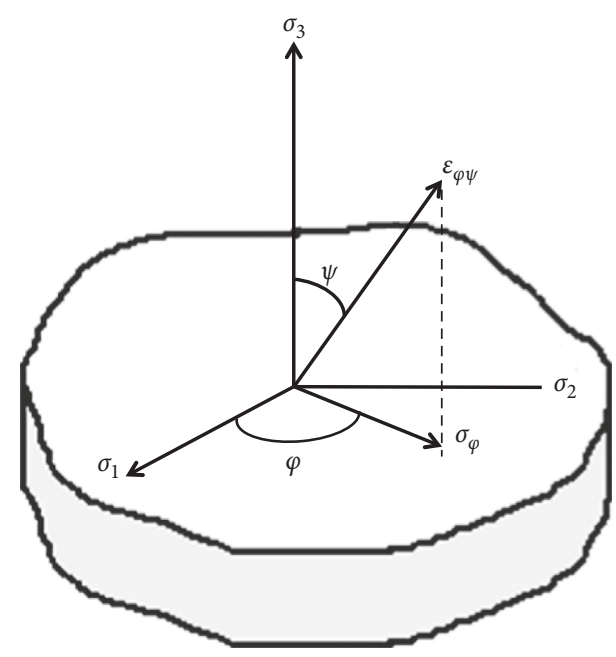

FIGURE 4: Strain component in arbitrary direction for three-dimensional stress state in polar coordinates.

the sample surface which guarantees the same distance between sample and X-ray tube focus.

The diffraction peak position is precisely determined with diffraction line processing. The initial stages of processing include experimental data filtering, background deleting, and fitting to the modified Cauchy distribution. The modified Cauchy function for the measured diffraction peak, when the doublet $K_{\alpha 1}$ and $K_{\alpha 2}$ is processed, can be expressed as

$$
y(x)=\frac{1}{\left(1+a(x-b)^{2}\right)^{n}}+\frac{0.5}{\left(1+a(x-b-\delta)^{2}\right)^{n}},
$$

where $a, b$, and $n$ are parameters related to the width, position, and growth rate of the function, respectively, and $\delta$ is the $K_{\alpha}$ interdoublet distance. Figure 6(a) shows the experimental diffraction line adjustment to the function expressed by equation (5). It can be seen a good fitting between the experimental (1) and the adjusted (2) diffraction profiles.

\section{Results and Discussion}

Optical microscopy analysis showed that the weld metal microstructure presented a coarse grain $\gamma$ (face centered cubic-FCC) matrix with cellular and dendritic solidification, with the cap pass microstructure finer than the root pass one. In the interdendritic regions, precipitates, such as Laves, $\mathrm{NbC}$, and complex $(\mathrm{Nb}, \mathrm{Ti})(\mathrm{C}, \mathrm{N})$, were formed [13]. The average grain sizes of the root and cap weld passes were $230 \mu \mathrm{m}$ and $200 \mu \mathrm{m}$, respectively. The coarser grain size in the root pass was due the higher heat input used to weld it and the lower heat transfer in this region. Both regions presented similar values of interdendritic and dendrites arm spacing, $12 \mu \mathrm{m}$ and $6 \mu \mathrm{m}$, respectively. The solidification grain boundary and dendrites of the root and cap weld passes of the Ni-based superalloy 625 weld metal can be seen in Figure 7 .

XRD stress measurements were performed with $K_{\alpha}-\mathrm{Cr}$ radiation and (220) crystallographic reflection plane. A $25 \mathrm{~mm} \times 25 \mathrm{~mm} \times 80 \mathrm{~mm}$ Ni-based superalloy 625 plate annealed at $1000^{\circ} \mathrm{C}$ for $1 \mathrm{~h}$ was used to test and calibrate the measurement system. The diffraction angle for unstressed $\mathrm{Ni}$ based superalloy 625 weld metal is equal to $\theta_{220}=64.595^{\circ}$. Figure 6(a) shows an example of experimental diffraction peak of this weld metal approximated with analytical function expressed by equation (5). For stress measurements, the $\psi$ angle tilts were varied in the interval from $0^{\circ}$ to $55^{\circ}$, with two intermediate positions $28^{\circ}$ and $42^{\circ}$, respectively. Final diffraction angle $\theta$ for each tilt position was determined as an average value from three repeated measurements; calculation uncertainty of diffraction line position with using the modified Cauchy function is equal to $2 \theta_{\text {calc }}=2 \theta_{\text {average }} \pm 0.005^{\circ}$.

The relation between $\theta_{\varphi \psi}$ and the $\sin ^{2} \psi$ in Figure 6(b) shows that the diffraction peak position for annealed Nibased superalloy 625 weld metal does not depend on the variation of $\psi$ angle, indicating absence of residual stresses in this sample.

For determination of the XRD residual stress on the cap weld passes on outside surface of $9 \% \mathrm{Ni}$ steel tubular joint after cleaning with steel wire brush, it is necessary the development of a novel technique to individually resolve the welding residual stresses and stresses introduced by brushing. The brushing process leads to an introduction of plastic deformation in surface layer of the weld metal and, for the inelastic region, the superposition concept must be modified. For this case, the stress component measured by XRD method can be expressed as

$$
\sigma_{\text {meas }}=\sigma_{\text {brush }}+a \sigma_{\text {weld }},
$$

where $\sigma_{\text {meas }}$ is the stress measured on the surface of the weld metal, i.e., originated by welding and brushing, $\sigma_{\text {brush }}$ is the residual stress after brushing on the unstressed specimen, $\sigma_{\text {weld }}$ is the true weld metal residual stress caused by welding process, and $a$ is the parameter taking into account the influence of the weld metal residual stress on the brushing process, similar to the effect of residual stress on hardness number [14]. For example, the parameter $a$ can be determined experimentally by residual stress measurements after brushing of plate sample loaded by bending on cylindrical supports. 




(a)

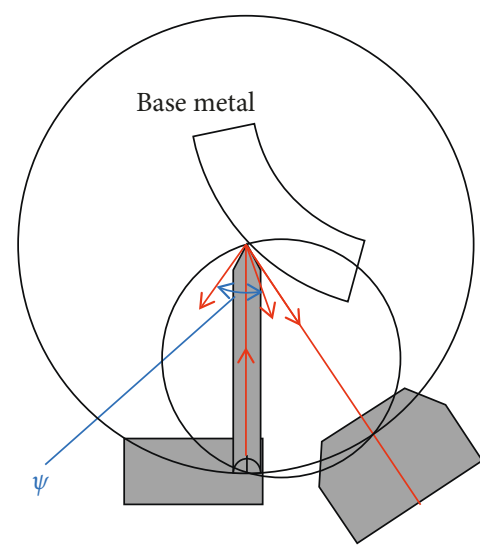

(b)

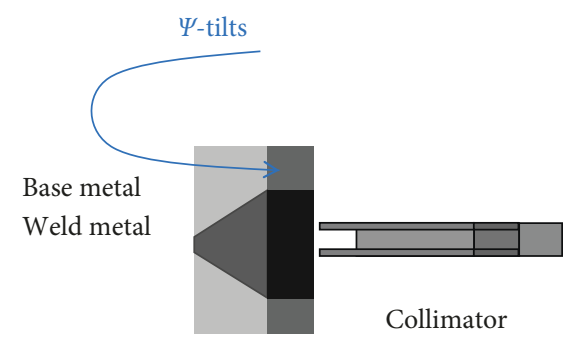

(c)

FIgURE 5: Illustration of longitudinal residual stress XRD measurements in various positions: (a) $\psi=0^{\circ}$, (b) $\psi=55^{\circ}$, and (c) special collimator view from point A. (1) Protective body with X-ray tube, (2) special collimator for incident beam, (3) analysed section of the $9 \% \mathrm{Ni}$ steel-welded pipe, (4) position-sensitive detector, and (5) focusing circles.

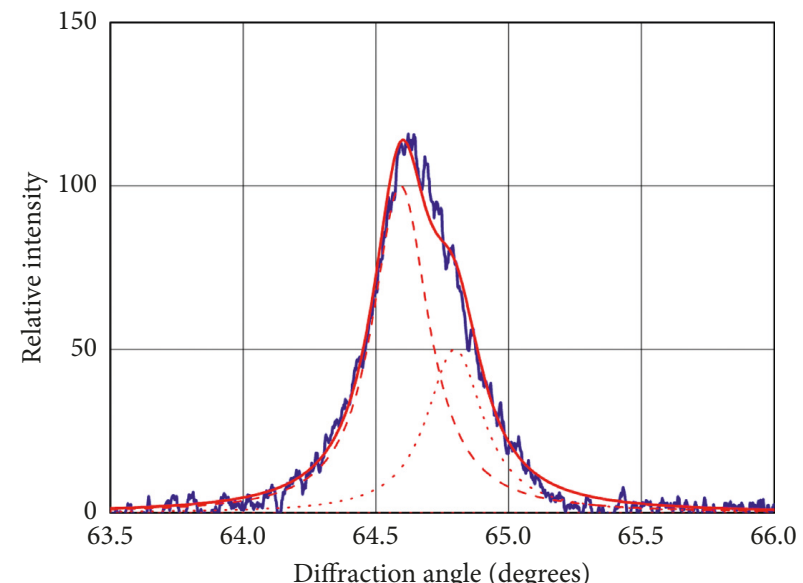

$\begin{array}{llll}\text { — Experimental data } & --- & \text { K } \alpha 1 \text { profile } \\ \text { — Fitted Cauchy curve } \quad \cdots . . . & \mathrm{K} \alpha 2 \text { profile }\end{array}$

(a)

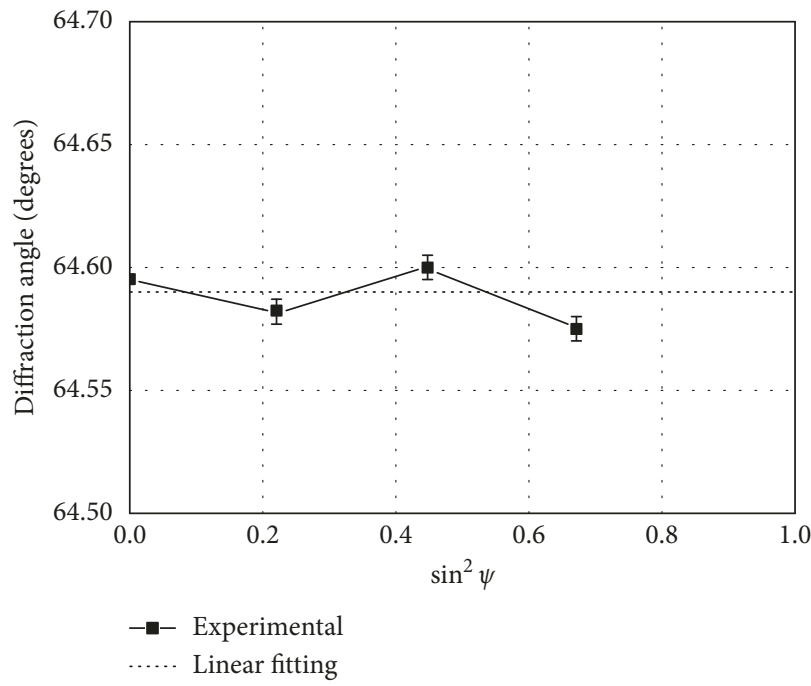

(b)

Figure 6: (a) Part of diffractogram of annealed Ni-based superalloy 625 weld metal and (b) the relation of the $\theta_{\varphi \psi}$ and the $\sin ^{2} \psi$ : (1) experimental profile; (2) analytical distribution applied for experimental profile fitting; components of analytical function (3) $K_{\alpha 1}$ and (4) $K_{\alpha 2}$.

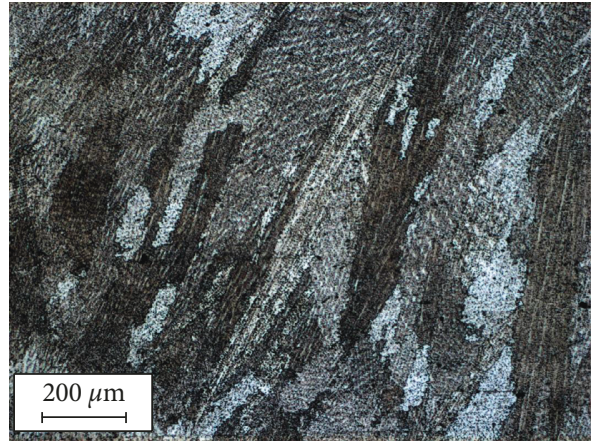

(a)

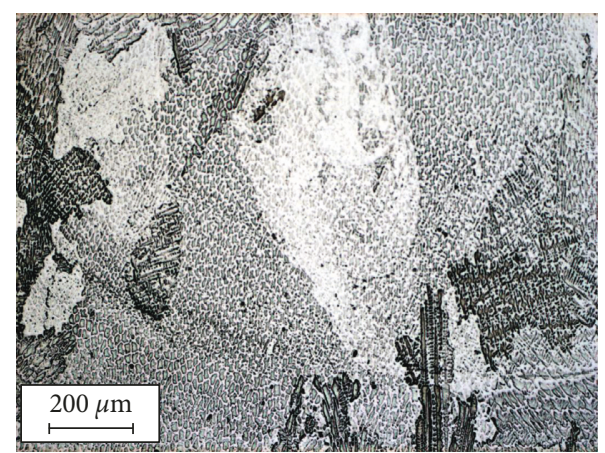

(b)

Figure 7: Optical microscopy of the Ni-based superalloy 625 weld metal: (a) root and (b) cap weld passes. 
Determination of $\sigma_{\text {brush }}$ was performed by experimental XRD measurement of residual stresses introduced in the $\mathrm{Ni}$ based superalloy 625 by brushing. For this purpose, a $25 \mathrm{~mm}$ $\times 20 \mathrm{~mm} \times 80 \mathrm{~mm}$ sample was machined from the Ni-based superalloy 625 and annealed at $1000^{\circ} \mathrm{C}$ for $1 \mathrm{~h}$. XRD measurements were performed before and after brushing. The brushing was executed manually by wire brush drill. Highspeed rotation guarantees reproducibility of brushing process. Series of XRD measurements of residual stresses, performed after brushing times from 10 to 60 seconds, showed difference of measured stress values within measurement error range.

Figure 6 presents the X-ray part of the diffractogram and the initial stress state of the annealed Ni-based superalloy 625 sample. The absence of residual stresses is evident and acceptable diffraction line was obtained (Figures 6(a) and 8(c)). After annealing, the surface of the Ni-based superalloy 625 sample was subjected to brushing in the same way as the $9 \% \mathrm{Ni}$ steel-welded joint and then was analysed by XRD technique.

The residual stress introduced by brushing $\left(\sigma_{\text {brush }}\right)$ was determined, and its value is compressive and equal to $-160 \mathrm{MPa}$. It is important to note that Ni-based superalloy 625 has high strength (yield strength and ultimate tensile strength at room temperature around $600 \mathrm{MPa}$ and $800 \mathrm{MPa}$, respectively). Because of this, plastic deformations caused by brushing are low.

The surface treatment of the weld metal with rotating stainless steel brush leads to appearing of diffraction line at all $\psi$ angles used in this work for XRD residual stress measurements. Figure 8 (b) shows this line at $\psi=0$. It can be seen that the broadening of diffraction line after brushing indicates the cold working process occurring due to brushing in plastically deformed thin surface layer. The example of transverse residual stress measurement in the root pass is presented in Figure 9.

EBSD analysis of the cap pass shows the weld metal solidifies preferentially parallel to the [001] direction and the upper region solidifies parallel to the [011] direction, as shown in the Figure 10(a). The change is due to different heat flow conditions within these regions. The Figure 10(b) shows that in a thin layer of approximately $15 \mu \mathrm{m}$ are observed several deformed grains containing substructure elements with different orientation. The kernel average misorientation (KAM) in the Figure 10(c) shows a higher degree of misorientation in superficial layer, indicating presence of deformation in this region.

Table 2 presents the measured weld metal residual stresses after brushing. The values of residual stress for the root pass weld metal were obtained after brushing of this region in the same way as the outside surface of the $9 \% \mathrm{Ni}$ steel weld metal.

The results of stress measurements presented in Table 2 show that only compressive transverse residual stress on the root pass weld metal presents absolute value higher than the residual stress absolute value of the brushed sample and all other compressive residual stresses are lower than the residual stress on the surface of brushed sample. Also, it can be seen that the values of all residual stresses are low compared with the yield stress of Ni-based superalloy 625 .

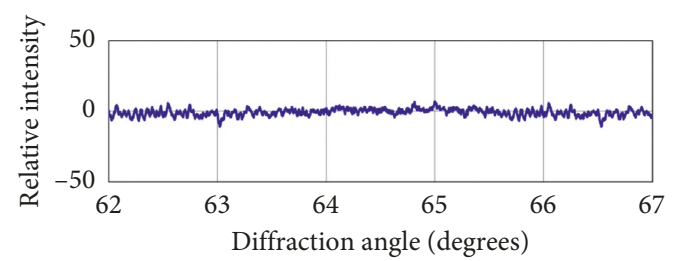

(a)

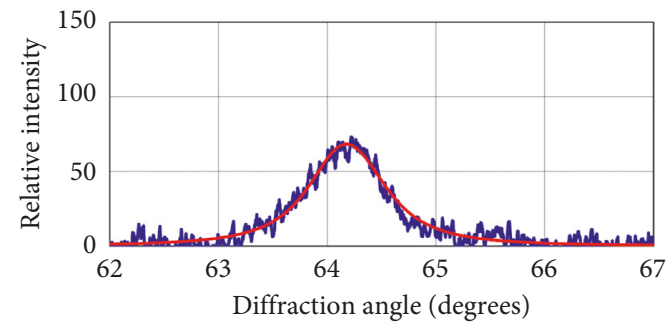

(b)

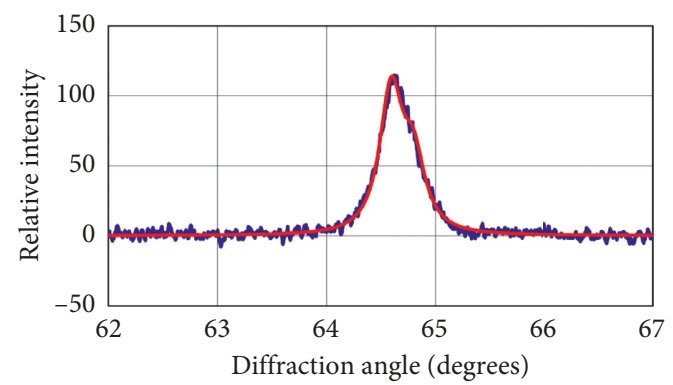

(c)

Figure 8: (a) Part of diffractogram for Ni-based superalloy 625 weld metal of the cap pass after electrolytic polishing or the root pass weld metal without brushing, (b) cap pass (location 1) after brushing, and (c) Ni-based superalloy 625 sample after annealing.

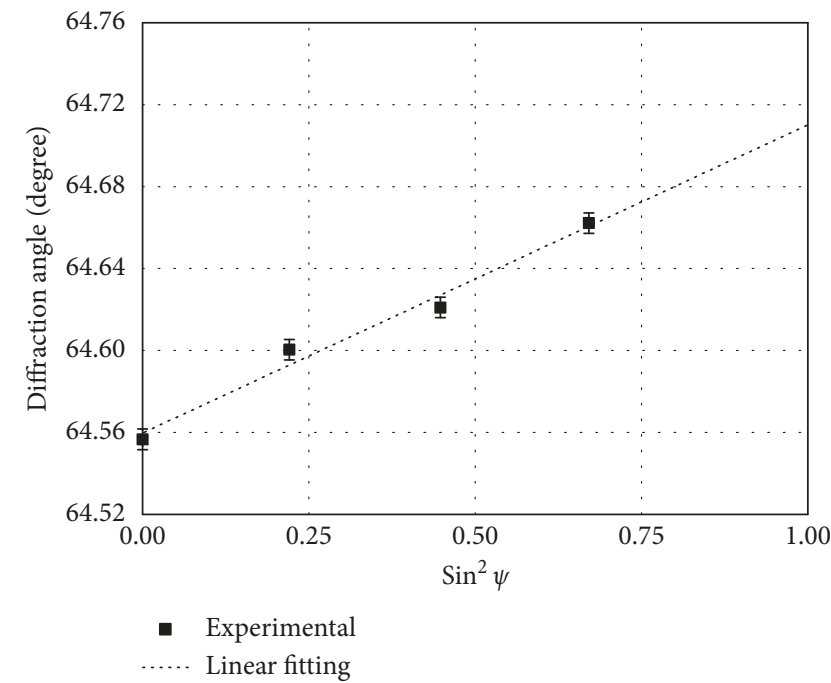

FIGURE 9: Experimental values and processed by linear regression of diffraction angle $\theta_{\varphi \psi}$ vs $\sin ^{2} \psi$ for transverse residual stress measurement in the root pass.

The nickel-based superalloy 625 presents an adherent, high-strength thin oxide layer that remains after brush cleaning of welding by-products. During stress measurements, 


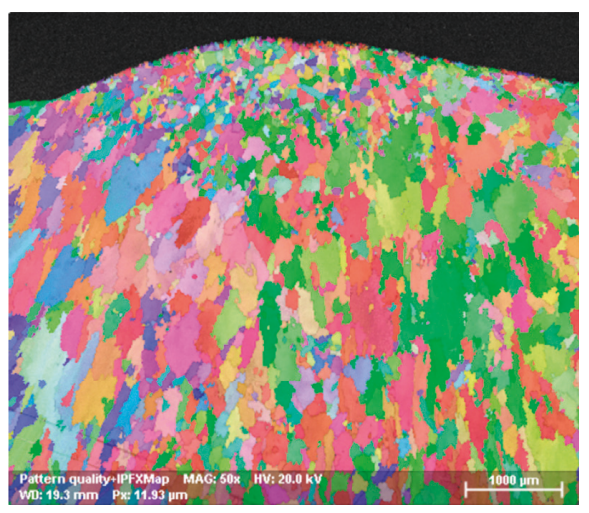

(a)

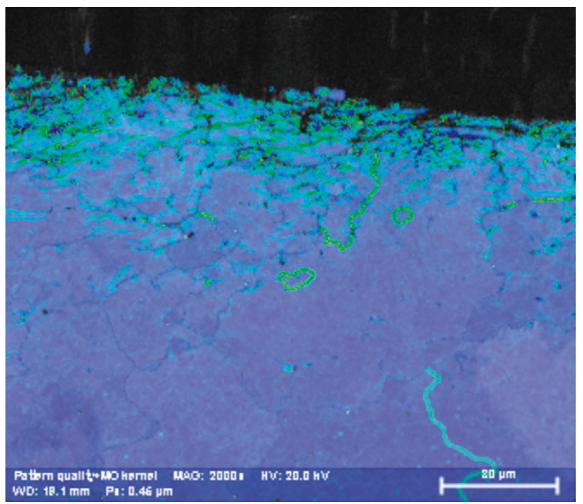

(c)

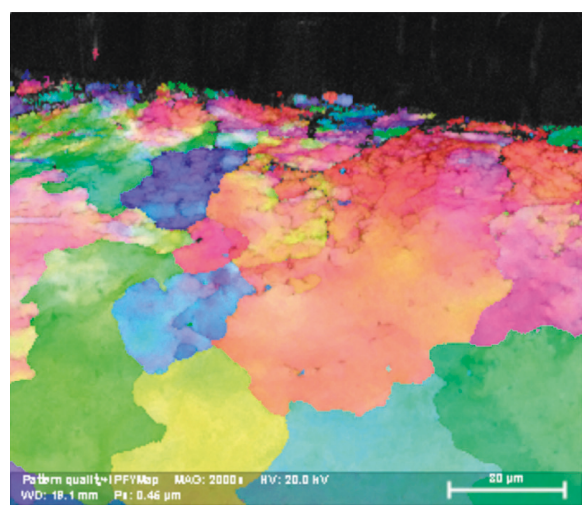

(b)

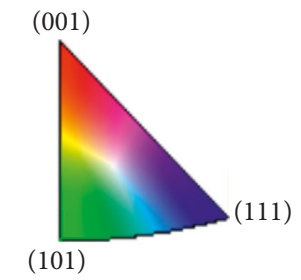

(d)

FIGURE 10: EBSD analysis of weld metal cap pass: (a) pattern quality and inverse pole figure map of the weld metal cap pass upper region, (b) pattern quality and inverse pole figure map of the weld metal superficial layer, and (c) pattern quality and kernel average misorientation map of the weld metal superficial layer.

TABLE 2: Transverse and longitudinal stresses in the cap and root passes of the Ni-based superalloy 625 weld metal.

\begin{tabular}{lcccc}
\hline \multirow{2}{*}{$\begin{array}{l}\text { Weld } \\
\text { pass }\end{array}$} & \multicolumn{4}{c}{ Residual stress $(\mathrm{MPa})$} \\
& Transverse & Longitudinal & Transverse & Longitudinal \\
\hline Cap 1 & -75 & -25 & +85 & +200 \\
Cap 2 & -70 & -50 & +95 & +130 \\
Cap 3 & -100 & -60 & +50 & +110 \\
Root & -215 & -80 & -55 & +75 \\
Sample & -160 & -160 & & \\
\hline
\end{tabular}

the X-ray beam penetrates the oxide layer and diffracts both in the distorted layer with $\sigma_{\text {brush }}$ and in part of the weld metal with $\sigma_{\text {weld }}$. Therefore, the surface of the weld metal characterised by these multiple stressed layers allows applying the methodology of diffraction line simulation for analysis of residual stress state in metals and alloys described elsewhere [15]. According to this methodology, the total diffraction profile represents the sum of profiles reflected separately by sequence of superficial layers with heterogeneously distributed residual stresses. The intensity of each individual profile depends on X-ray absorption and $\psi$ tilts and can be expressed by the following equation:

$$
I_{\text {dif }}=\alpha I_{0} e^{-\mu z}=\alpha I_{0} e^{-\mu t((1 / \cos (\psi+90-\theta))+(1 / \cos (\psi-90+\theta)))} .
$$

The angular positions of individual profiles can be determined by equation (3):

$$
\theta_{\psi}=\theta_{0}+\sigma(t) \frac{(1+\nu)}{E} \frac{\sin ^{2} \psi}{\cot \theta_{0}}-\frac{\nu}{E}\left(\sigma_{1}+\sigma_{2}\right) .
$$

In this work, the constant stress $\sigma_{\varphi}$ in equation (3) is substituted by stress distribution function $\sigma(t)$, where $t$ is the depth of diffraction layer. Equations (7) and (8) are used for computer simulation of diffraction profile applied to determination of residual stress in weld metal. Figure 11 presents all stages of simulation process.

The tensile stresses in weld metal varied during simulation process in the interval between $50 \mathrm{MPa}$ and $200 \mathrm{MPa}$ (curves 3 and 4 in the Figure 11(a)). Taking into account that the compressive residual stress equal to $-160 \mathrm{MPa}$ is the stress introduced by brushing plastic distortions $\left(\sigma_{\text {brush }}\right)$, an elastic distorted region is assumed to occur in the layer between the distorted and the undistorted layers. These regions are shown in the Figure 11(a) as regions I, II, and III.

The regions I and III are under the action of $\sigma_{\text {brush }}$ and $\sigma_{\text {weld }}$ residual stresses, respectively, and region II can be characterised as transitional from compressive to tensile residual stresses. Simulation process includes determination of angular position of total diffraction line, as shown in Figures 11(b) and 11(c), and the calculation of residual stress value corresponding to the straight line slope (line 2 in 


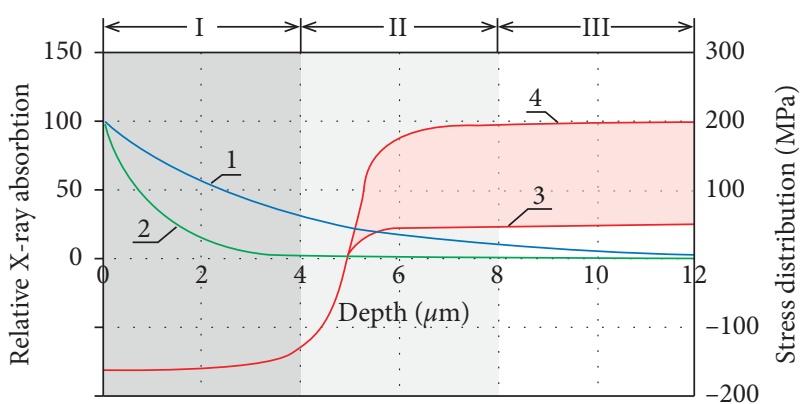

(a)

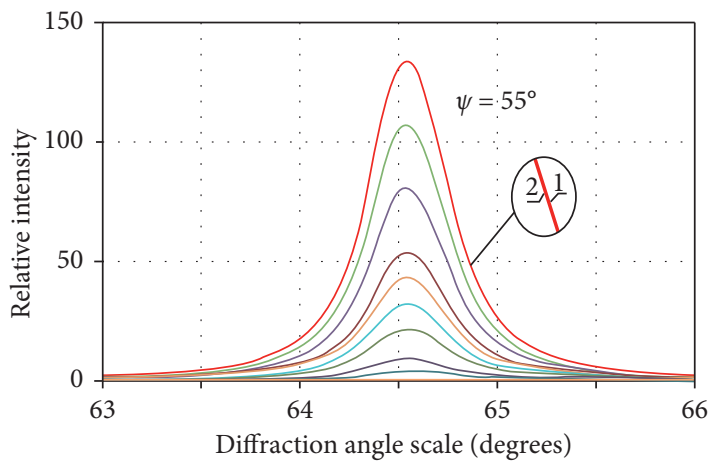

(c)

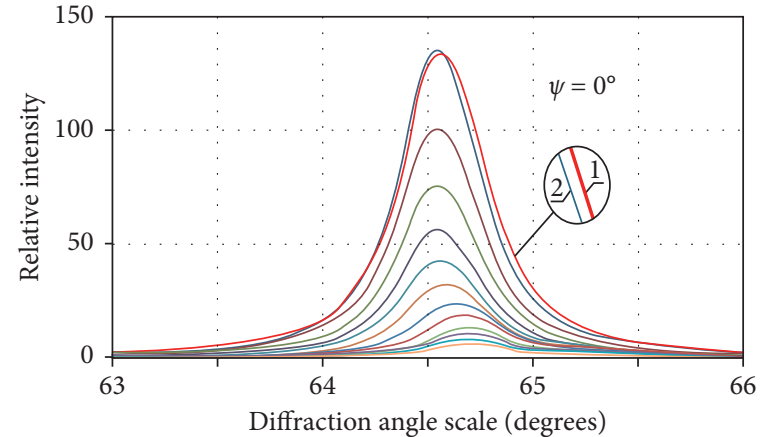

(b)

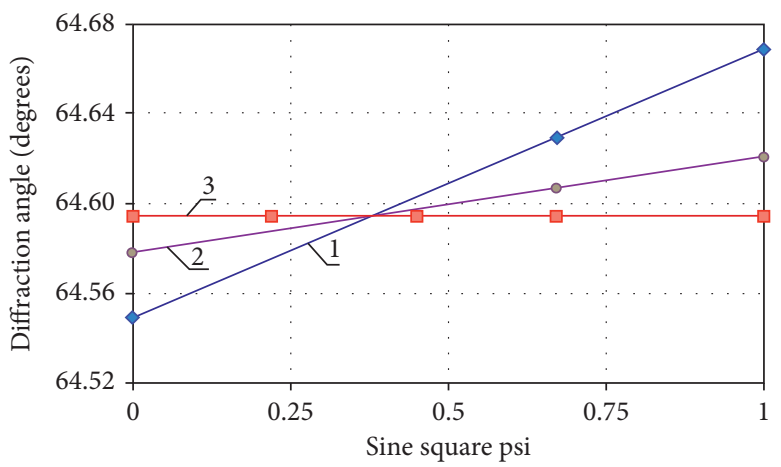

(d)

FIGURE 11: Computer simulation used for residual stress determination in Ni-based superalloy 625 weld metal: (a) X-ray diffraction intensities expressed by equation (7) where 1 and 2 are intensities for $\psi$ tilts equal to $0^{\circ}$ and $55^{\circ}$ and residual stress distributions and 3 and 4 are stress distribution for $\sigma_{\text {weld }}$ equal to $50 \mathrm{MPa}$ and $200 \mathrm{MPa}$, respectively; (b, c) procedures of diffraction line simulation where 1 and 2 are the total and the first layer diffraction profiles, respectively; (d) stress determination by " $\sin ^{2} \psi$ method" where 1,2 , and 3 are the functions $\theta_{\varphi \psi}=f\left(\sin ^{2} \psi\right)$ for constant residual stress introduced by brushing, obtained by simulation, and for annealed weld metal, respectively.

Figure 11(d)) and selected stress distribution with tensile $\sigma_{\text {weld }}$ between $50 \mathrm{MPa}$ and $200 \mathrm{MPa}$. The equality between the calculated stress value and the measured stress value, presented in Table 2, confirms assertiveness of selected $\sigma_{\text {weld }}$. Otherwise, the iteration method is used until the coincidence of measured and simulated stress values.

Due to fact that plastic deformation caused by brushing of surface layer is low, then the concept proposed for using of brushing for stress measurements in coarse grain and preferentially oriented microstructure may be expressed as following. The brushing should generate enough stress to produce modification on the coarse grained microstructure and reestablish the X-ray diffraction pattern. For weld metals with lower strength, it can be used low strength brush material as brass or nylon.

Table 2 shows that both longitudinal and transverse residual stresses in the weld metal of cap passes (locations 2, 3, and 4 in Figure 2(b)) are tensile indicating that the shrinkage effect is the principal cause of residual stresses arising in the analysed weld metal. In the root pass weld metal, the longitudinal stress is also tensile but the transverse stress is compressive. These experimental data are not contradictory to equilibrium conditions consisting in the equality to zero of resultant of internal forces and moments produced by residual stresses. In terms of stress, the equilibrium of solids can be expressed as

$$
\begin{gathered}
\int_{A} \sigma(x, y) d A=0, \\
\int_{A} \sigma(x, y) r d A=0,
\end{gathered}
$$

where the integration is performed over the cross section area $A$. It is important to note that cross sections for equilibrium of the internal forces resultant are perpendicular to the direction of analysed residual stress. For example, equilibrium of internal forces produced by transverse residual stress at the centre of the weld metal should be analysed in the plane which normal is perpendicular to the welding direction. Figure 12 illustrates cross sections needed for analysis of equilibrium for longitudinal and transverse residual stresses. Figure 12(c) shows that tensile transverse stresses on the outer weld metal surface must be balanced by compressive stresses in its inner surface. This condition for transverse stress distribution in weld metal does not apply for longitudinal residual stresses because the balance occurs between tensile longitudinal stresses in weld metal and compressive stresses in base metal (Figure 12(b)).

Because there was no access to the weld metal on inner surface for the XRD stress analysis, it was necessary to section the welded pipe to perform the residual stress measurements. This sectioning changes the welded joint residual stress state. Figure 12(d) shows the emergence of 


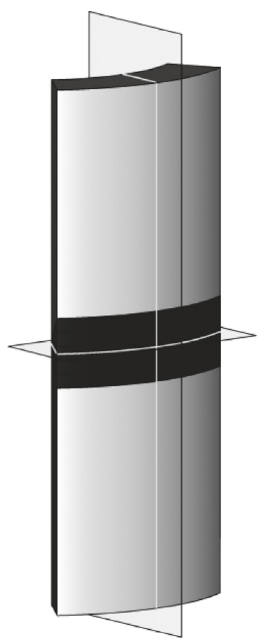

(a)

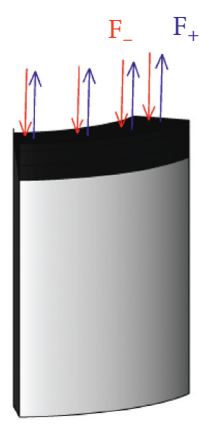

(c)

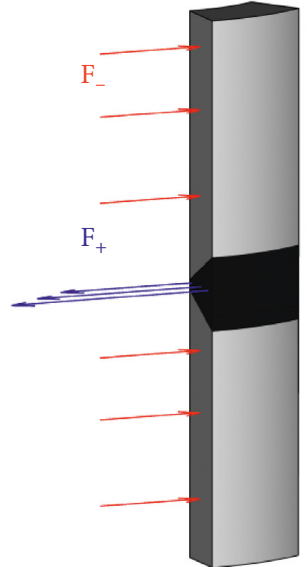

(b)

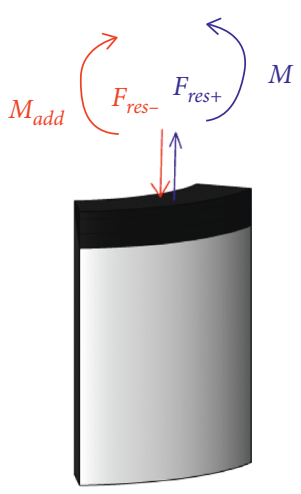

(d)
Figure 12: (a) Cross sections for analysis of equilibrium for internal forces produced by (b) longitudinal and (c) transverse residual stresses; $F_{+}, F_{-}$and $F_{\text {rest }}, F_{\text {res- }}$ are internal tensile and compressive forces (c) and their resultants (d), respectively; $M_{\text {add }}$ is the additional moment that balances with the moment $M$ of resultants $F_{\text {rest }}$ and $F_{\text {res- }}$.

additional moment $M_{\text {add }}$ that balances with the moment $M$ of resultants $F_{\text {res+ }}$ and $F_{\text {res- }}$ of internal forces produced by tensile and compressive transverse residual stresses. Additional bending stresses generated by $M_{\text {add }}$ are a result of the pipe sectioning. In the case of uncut welded pipe, the moment $M$ on one side of the pipe is balanced due to symmetry with opposite $M$ on the other side.

\section{Conclusions}

The surface treatment by rotating steel wire brush, and consequently plastic deformation of a thin weld metal layer, leads to the appearance of X-ray diffraction lines from microstructure with initially coarse and preferentially oriented grains.

The developed technique based on soft cold work hardening by plastic deformation of a thin superficial layer of the weld metal that is sufficient to apply computer simulation for determination of the weld residual stress by XRD technique.
The presence of compressive transverse residual stress in the root weld metal is in agreement with the equilibrium equation for internal forces produced by transverse residual stress.

The transverse residual stress was modified after the welded joint sectioning and because of this, an additional moment emerged to establish the equilibrium in the welded joint section.

\section{Data Availability}

The residual stress measurements data used to support the findings of this study are available from the corresponding author upon request.

\section{Conflicts of Interest}

No potential conflicts of interest were reported by the authors.

\section{Acknowledgments}

The authors are also grateful for the $9 \% \mathrm{Ni}$ steel pipe provided by VSB (Vallourec Soluções Tubulares do Brasil) and for the welded joint supplied by IST Solda (Instituto Senai de Tecnologia Solda). The authors would like to thank Empresa Brasileira de Pesquisa e Inovação Industrial (award number PCOP-1512.0004) and Shell Brasil (award number T0821) for funding.

\section{References}

[1] P. J. Withers and H. K. D. H. Bhadeshia, "Residual stress. Part 2-nature and origins," Materials Science and Technology, vol. 17, no. 4, pp. 366-375, 2013.

[2] K. Masubichi, Analysis of Welded Structures: Residual Stresses, Distortions and their Consequences, Pergamon Press, Oxford, UK, 1980.

[3] S. J. Maddox, Influence of Tensile Residual Stresses on the Fatigue Behavior of Welded Joints in Steel, Residual Stress Effects in Fatigue, ASTM STP 776, Philadelphia, PA, USA, 1982.

[4] M. N. James, P. J. Webster, D. J. Hughes et al., "Correlating weld process conditions, residual strain and stress, microstructure and mechanical properties for high strength steelthe role of neutron diffraction strain scanning," Materials Science and Engineering: A, vol. 427, no. 1-2, pp. 16-26, 2006.

[5] A. De and T. DebRoy, "A perspective on residual stresses in welding," Science and Technology of Welding and Joining, vol. 16, no. 3, pp. 204-208, 2013.

[6] N. S. M. Nasir, M. K. A. A. Razab, S. Mamat et al., "Review on welding residual stress," ARPN Journal of Engineering and Applied Sciences, vol. 11, no. 9, pp. 6166-6175, 2016.

[7] P. J. Withers and H. K. D. H. Bhadeshia, "Residual stress. Part 1-measurement techniques," Materials Science and Technology, vol. 17, no. 4, pp. 355-365, 2013.

[8] T. Gnaupel-Herold, P. Mikula, S. K. Paranjpe et al., "Measurement of residual stress in materials using neutrons," in Proceedings of IAEA Technical Meeting, IAEA-TECDOC-1457, Vienna, Austria, October 2003. 
[9] M. E. Fitzpatrick, A. T. Fry, P. Holdway et al., Determination of Residual Stresses by X-Ray Diffraction, NPL, Vol. 52, NPL, Teddington, UK, 2002.

[10] V. Luzin, H. J. Prask, T. Gnaupel-Herold, and S. Sampath, "Use of neutron diffraction for stress measurements in thin and thick thermal sprayed coatings," International Heat Treatment and Surface Engineering, vol. 4, no. 1, pp. 17-24, 2010.

[11] B. P. Conroy and D. A. Tanner, "Determination of residual stress within complex-shape coarse-grained cobalt-chromium biomedical castings," Materials Science and Technology, vol. 32, no. 14, pp. 1411-1426, 2016.

[12] B. Conroy, Y. Traoré, S. Paddea et al., "Application of multiple residual stress determination methods to coarse-grained biomedical implant castings," Materials Science and Technology, vol. 33, no. 10, pp. 1231-1251, 2017.

[13] C. C. Silva, H. C. Miranda, M. F. Motta et al., "New insight on the solidification path of an alloy 625 weld overlay," Journal of Materials Research and Technology, vol. 2, no. 3, pp. 228-237, 2013.

[14] J. Frenkel, A. Abbate, and W. Schole, "The effect of residual stresses on hardness measurements," Experimental Mechanics, vol. 33, no. 2, pp. 164-168, 1993.

[15] V. I. Monin, J. T. Assis, and S. M. Iglesias, "Study of superficial stress gradients by computer simulation and $\mathrm{x}$-ray diffraction experiment," A. I. Melker and V. V. Nelayev, Eds., in Proceedings of the Twelfth International Workshop on Nanodesign Technology and Computer Simulations, SPIE 7377; 2009, Minsk, Belarus, July 2008. 


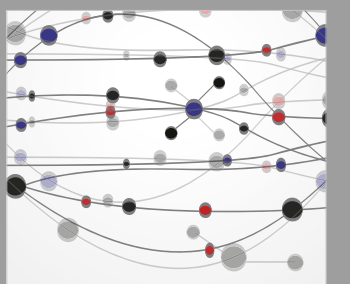

The Scientific World Journal
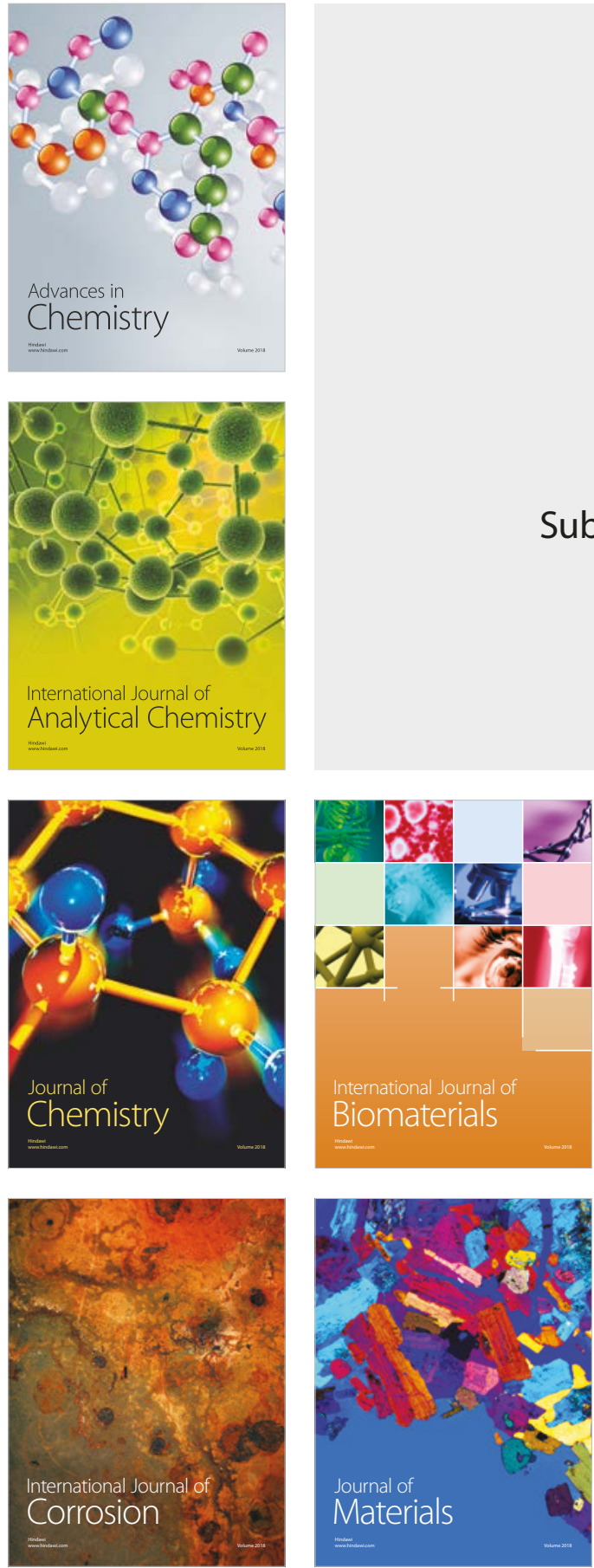

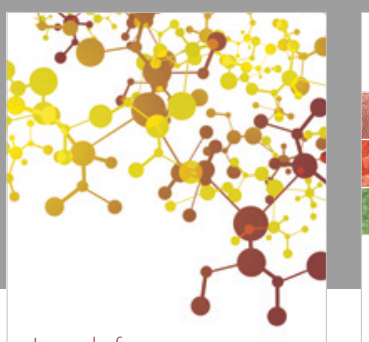

Journal of

Applied Chemistry
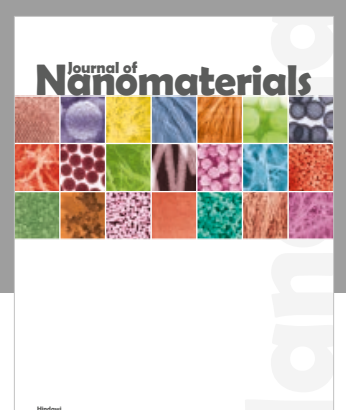

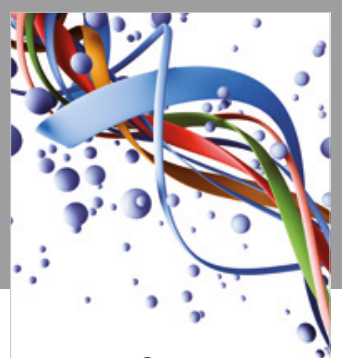

Scientifica

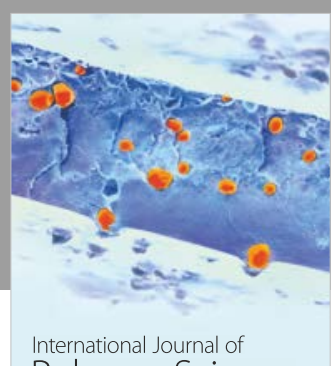

Polymer Science

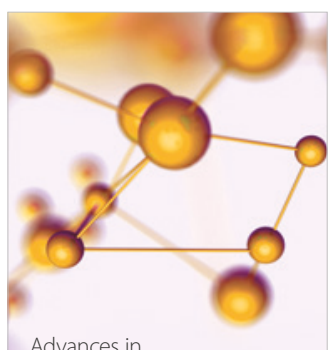

Physical Chemistry
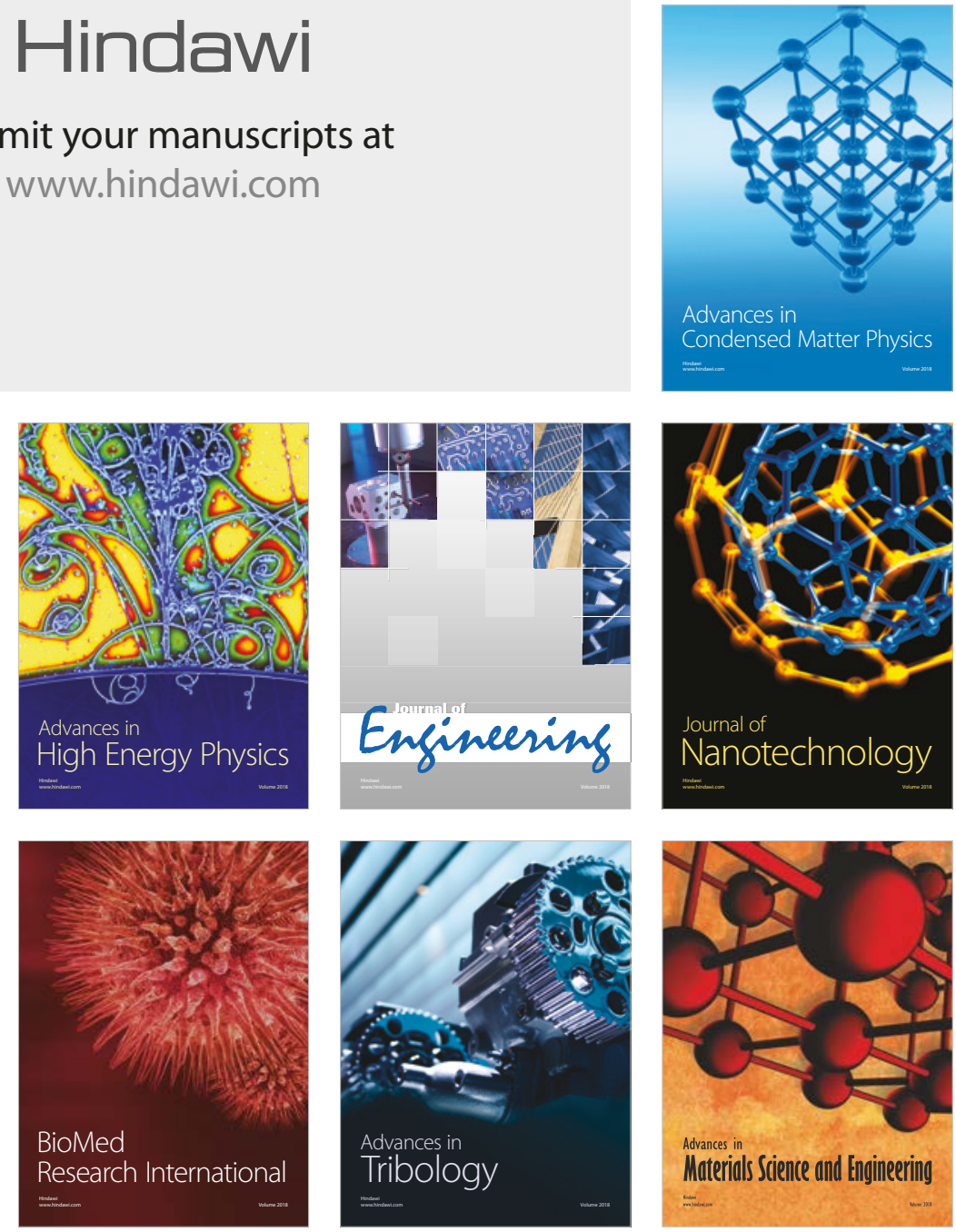